\title{
The Present and Future of Standards for E-Learning Technologies
}

\section{Iraklis Varlamis Athens University of Economics and Business, Athens, Greece}

\author{
Ioannis Apostolakis \\ Technical University of Crete, \\ Greece
}

varlamis@aueb.gr

apost@ced.tuc.gr

\begin{abstract}
This paper studies the e-learning technologies from the standardization aspect with a glimpse on future changes. Our aim is to thoroughly review the existing standards, the e-Learning process workflow and the market needs and trends and indicate the best path for achieving a global standard for e-learning activities. The generic model of e-learning is presented without emphasis on specific software and hardware solutions. We focus on the major necessities like reusability or interoperability of content and technologies and revise the current standards regarding these two aspects. The most popular infrastructure models are presented in details and the related committees and organizations involved in the standardization process are referenced. As an epilogue to this presentation we provide our insights for a global standard, which will cover all aspects of elearning and will be supported by all related organizations, vendors, institutions and individual educators. We illustrate the steps for the successful configuration and deployment of a globally accepted standard and display the merits of this approach.
\end{abstract}

Keywords: e-Learning standards, reusability, interoperability, learning objects, unification of standards.

\section{Introduction}

In the era of information abundance, diversity and distribution it is crucial for individuals and organizations to put things in order by defining standards for everything. Following the trend, the developers, vendors and users of e-learning systems develop, support and adopt standards for the overall learning process. As it happens with every community, e-learning is now shifting from the chaotic "no standards" stage, to the phase of rules' and standards' definition in an attempt to avoid the Babel syndrome. From the first moment of this phase, pioneers of the e-learning community cooperated in order to define standards, protocols and architectures for the

Material published as part of this journal, either on-line or in print, is copyrighted by the publisher of the Interdisciplinary Journal of Knowledge and Learning Objects. Permission to make digital or paper copy of part or all of these works for personal or classroom use is granted without fee provided that the copies are not made or distributed for profit or commercial advantage AND that copies 1) bear this notice in full and 2) give the full citation on the first page. It is permissible to abstract these works so long as credit is given. To copy in all other cases or to republish or to post on a server or to redistribute to lists requires specific permission and payment of a fee. Contact Publisher@ijklo.org to request redistribution permission. development of e-learning content, services and products. International consortia comprising standardization organizations, institutes and software houses undertake the coordination of players in the e-learning market chain. They collect user requirements, issue specifications for e-learning systems, develop and test applications, which validate the user requirements and convert the approved specifications 
into standards.

In order to boost the gains of e-learning market we must develop learning components (Namuth, Fritz, King, \& Boren, 2005) that interoperate and co-operate. An e-learning process comprises conceptual and physical components and procedures that should be both standardized in terms of procedures and technologies. Development, through the whole lifecycle of e-learning process, must be done in the basis of widely adopted standards (Lytras \& Sicilia, 2005). As far as it concerns the conceptual background of an e-learning application the issues that must be well defined are: a) the design of the e-learning process, b) the definition of learners' competencies, c) the framework for the co-operation among teachers and educates. The physical components comprise: a) the learning content and its packaging and deployment, b) the learners' profile, c) the assessment activities, d) the metadata structure and e) the system architecture.

International organizations, software houses and universities develop standards that cover all aspects of e-learning. However, such standards usually fit to the needs of specific applications and are inadequate for supporting the interoperability of e-learning (Friesen, 2005). The development of proprietary tools that use custom standards and protocols should be discouraged since it generates confusion and decelerates the growth of e-learning communities, as it was the case with multimedia technologies.

The definition and adoption of complete and sound e-learning standards will help the e-learning market achieve some key goals:

- Users of e-learning applications will be able to shift between programs and platforms, to find those that fit their needs with minimal transition cost. Moreover, the learners gain in flexibility since the attained knowledge can easily migrate to future e-learning platforms that follow the same standards. To put it simple, once the user familiarizes with a standardized e-learning technology it becomes easier to familiarize with any variation of this technology.

- Learning content producers will focus on the development of content in a standard format instead of developing the same content into many formats for different platforms and applications.

- Tool vendors will not spend money for the development of interfaces that glue their tools to e-learning platforms and systems. Lower development costs imply less expensive tools of better quality and subsequently an increase in the size of the potential market.

- Application and platform designers are able to choose from a large storehouse of reusable content, systems and tools and assembled a competitive and effective e-learning platform. They can also populate the storehouse with new modules of content and applications.

The main objective of this work is to define the framework for the development of global elearning standards that support interoperability of e-learning systems. To achieve this, it is essential to understand the innermost of e-learning process: its lifecycle and its infrastructures as presented in the next section. Next it is necessary to judge on the usability and re-usability of existing work on standards and present the general steps of our approach. Finally, it is important to understand how standards adhere to the interoperability of e-learning systems. This is explained in the fourth section, which presents the most important e-learning interoperability standards. In the conclusion we present a roadmap for the creation of widely accepted e-learning standards. 


\section{Inside the E-Learning Process}

In order to reason the need for standards and interoperability in e-learning systems we should be aware of the lifecycle of the e-learning process and have an overview of the components of elearning systems and their functionality. In the following we illustrate the stages of a learning process, present the building blocks of an e-learning environment and provide a general model that comprises of the different services that e-learning technologies provide. We explain how the building blocks fit together into an overall e-learning application infrastructure and give a functional overview of the processes that make up an e-learning environment.

\section{The Life-Cycle of the E-Learning Process}

The life-cycle of the e-learning process from the planning and preparation of a course to the consumption by the learners is depicted in Figure 1. The life cycle, as presented in Figure 1, comprises of four phases, namely: the design phase, where the targets and requirements are specified, the production phase, where content is produced, assembled and packaged for distribution, the deployment phase, which requires the collaboration of learners in order to distribute the appropriate content per case, and the assessment phase, where the outcome of the whole process is evaluated.

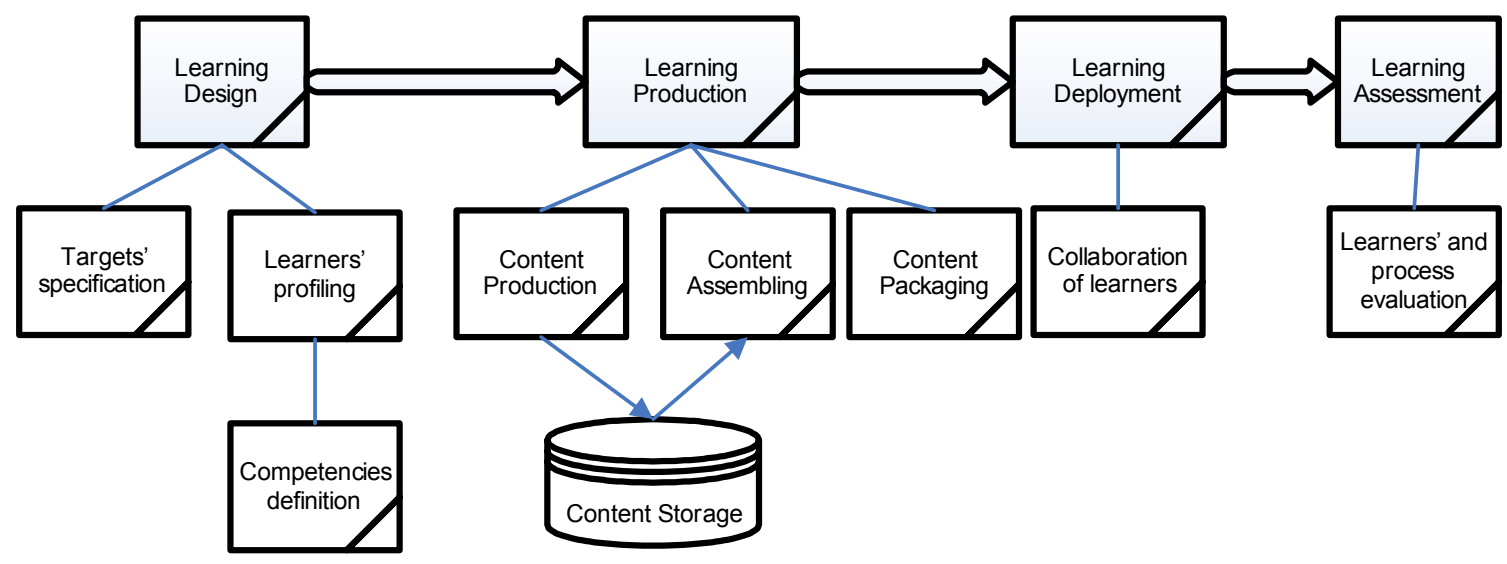

Figure 1. The life cycle of the e-learning process

For the successful design of a learning process one should first define the required features of learners' profile and the recommended competencies. It should also specify in detail the educational targets to be achieved by the end of the learning process. The production phase integrates the production of content modules, their build up based on the initial design, and the packaging of the content to be delivered. The deployment phase that follows should consider the ability of users to access the content and collaborate during the learning process. The learning process ends up with the assessment of learners through tests and other activities and of the process itself through evaluation forms.

At the end of every phase useful information is collected and fed back to every previous phase of the process. This facilitates the improvement of the whole process and leads to better solutions for learners and educators. As an example, the information gathered during the deployment phase, which concerns actual learners' needs and level of satisfaction is used as an input in the production phase, in order to reassemble learning objects and produce more competitive packaged solutions. 
The learning process described above encompasses the issues of interoperability and standardization of tasks.

- During the whole lifecycle, from the design of a course to the final assessment there is a strong influence between tasks. The learners profile is strongly related to the competencies required by the learning process and consequently affects the educational targets. Similarly, the delivery of content requires synchronization of content production, assembly and packaging tasks and so on.

- The first requirement for controlling the process is the semantic interoperability of tasks. The interoperability should be built on well tested and widely adopted standards. Standards enable teachers and learners to better understand each other. Concepts employed by teachers for the design of the learning process, for the specification of educational targets and the definition of required skills should be communicated and understood by the users. Partners that provide, assemble, and deliver content should be aware of the educational targets and the targeted audience.

- In a more technical level systems that produce, process, and distribute learning content must cooperate and exchange information based on standards. The development of systems by many vendors without following any standards leads to the fragmentation of incompatible technologies. As a result we have systems that cannot cooperate and content that cannot be reused.

- Standards would impose some requirements on how to create content or on how to define a procedure or a user profile. However, they would by no means limit the creativity of the designers.

From the above, it becomes clear that in order to minimize development and deployment costs, to facilitate re-usability of content and increase effectiveness of the learning process we should first resolve all technical issues and achieve interoperability of technologies and systems. The resolution of technical issues that arise can be performed in the basis of common standards and will allow us to focus on the educational aspects of learning.

\section{E-Learning Systems Infrastructure}

The elementary particles of an e-learning system are the "learning objects" (Wiley, 2002). They are the key definition to understanding an e-learning system structure as well as the core of reusability, interoperability and adaptability. From an operational perspective, learning objects are chunks of data that are used by e-learning system. They are authored, stored, indexed, assembled, delivered, and evaluated. A more realistic approach is to think of a learning object as a digital part of a course ranging in size and complexity from a single graphic to an entire course itself.

According to earlier methodologies, learning was organized into lessons and courses with predefined objectives. Recent paradigms require the breaking of content into much smaller, selfcontained pieces of information that can be used alone or can be dynamically assembled into Learning Objects (Cohen \& Nycz, 2006) to meet the "just enough" and "just-in-time" requirements of a learner (Bransford, Brown, \& Cocking, 2000)

The parallelism of learning objects to the LEGO building blocks is straightforward (Wiley, 1999). The individual LEGO blocks can represent smaller pieces or basic--raw content that grouped form an asset. In the case of learning, raw objects can be audio, video, text, graphics etc. Raw objects can be used for different types of assets. For example, a photo could be used on a presentation screen but it could also be used in a multiple choice question. These assets can be snapped together and pulled apart as needed, enabling almost infinite flexibility to create logical assemblies of individual content objects to meet the learning needs of individuals. The assets begin to 
take on properties and functionality and are then ready to be assembled into Learning Objects. In the SCORM standard (SCORM, 2005), these content objects are referred to a Sharable Content Objects or SCO's.

Learning objects can be developed easily and stored in repositories. However, for a successful design we should always have in mind re-usability. In order to create learning objects that can be managed, re-used and assembled in a complete learning process, we should first understand the conceptual model of content objects.

\section{The Conceptual Model behind Learning Objects}

The conceptual model of content object (Bohl, Schellhase, Senler, \& Winand, 2002) to which the learning objects perfectly fit describes a hierarchy of granular content (Figure 2, based on (Masie, 2002)). Within a series of levels of granular content, very small raw content assets (individual fact, principle, concept, example, procedure, etc.) can be assembled into a "just right" Learning Object. Each content asset is selected and assembled to match the unique needs of each person and situation, then presented just the right way, in just the right medium, at just the right time. This requires from content objects to be self-contained, self-descriptive and mutable (Pukkhem \& Vatanawood, 2005). More specifically, the conceptual model of content object describes:

- A component based approach.

- Structured content based on a hierarchical model.

- Metadata at each level of the content hierarchy.

- A process methodology.

- A technical infrastructure for developing, assembling and managing re-usable granular content objects that are written independent of delivery media and accessed dynamically through a database.

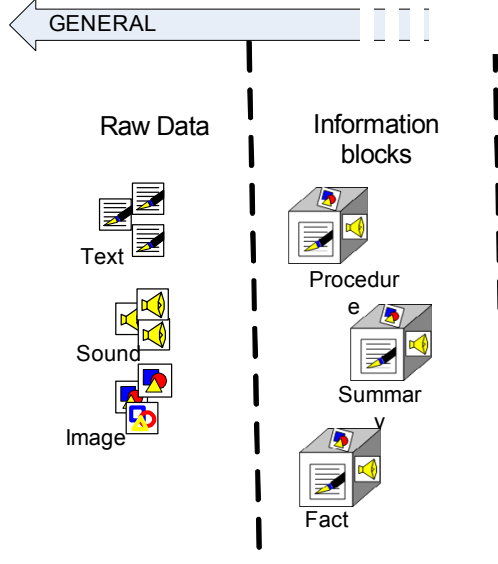

MOST REUSABILITY

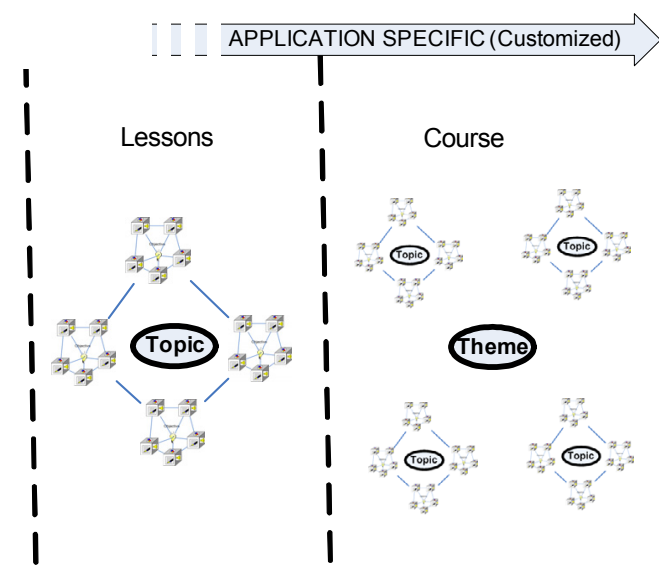

MOST CONTENT

Figure 2. Content Object Model

\section{Metadata}

Learning content stored across multiple repositories must be labeled in a consistent way to support the indexing, storage, search and retrieval tasks of the various educational tools. Data used 
for this purpose is referred to as Learning Object Metadata (LOM) (LOM, 2002) while metadata as a term generally means information about data or data-about-data.

\section{Context + Re-usability}

The content object model delivers a high degree of re-usability (Barritt \& Alderman, 2004) and context which are both extremely valuable. Context is a necessity in the learning process and is directly proportional to the effectiveness of the content and re-usability is strongly related to the return on investment in content.

The end result of content creation process is a database of information objects with metadata. The re-usability of such raw asset is high however the context they convey is limited. Objects are available in common media delivery types such as print, interactive CDs and web sites and can be easily re-used in all forms of learning such as: e-learning, traditional instructor-led training, or blended learning solutions. The assembly of loose assets into concrete lessons and courses puts learning into context but limits reusability

The raw information blocks are of little use to the learning process if examined as units. They are not bound to any specific application but are organized in hierarchies and are self-descriptive due to metadata. The learning design (Phase 1 in Figure 1) is responsible for adding context to the small information blocks by assembling them into learning objects. Learning objects stand in between raw information and stable courses. They still have great re-usability since they are not bound to a specific application or system, they are rich in content since they incorporate many resources and the convey context that serve general learning needs. Thus, the previous dichotomy between re-usability and context is resolved. (Figure 3).

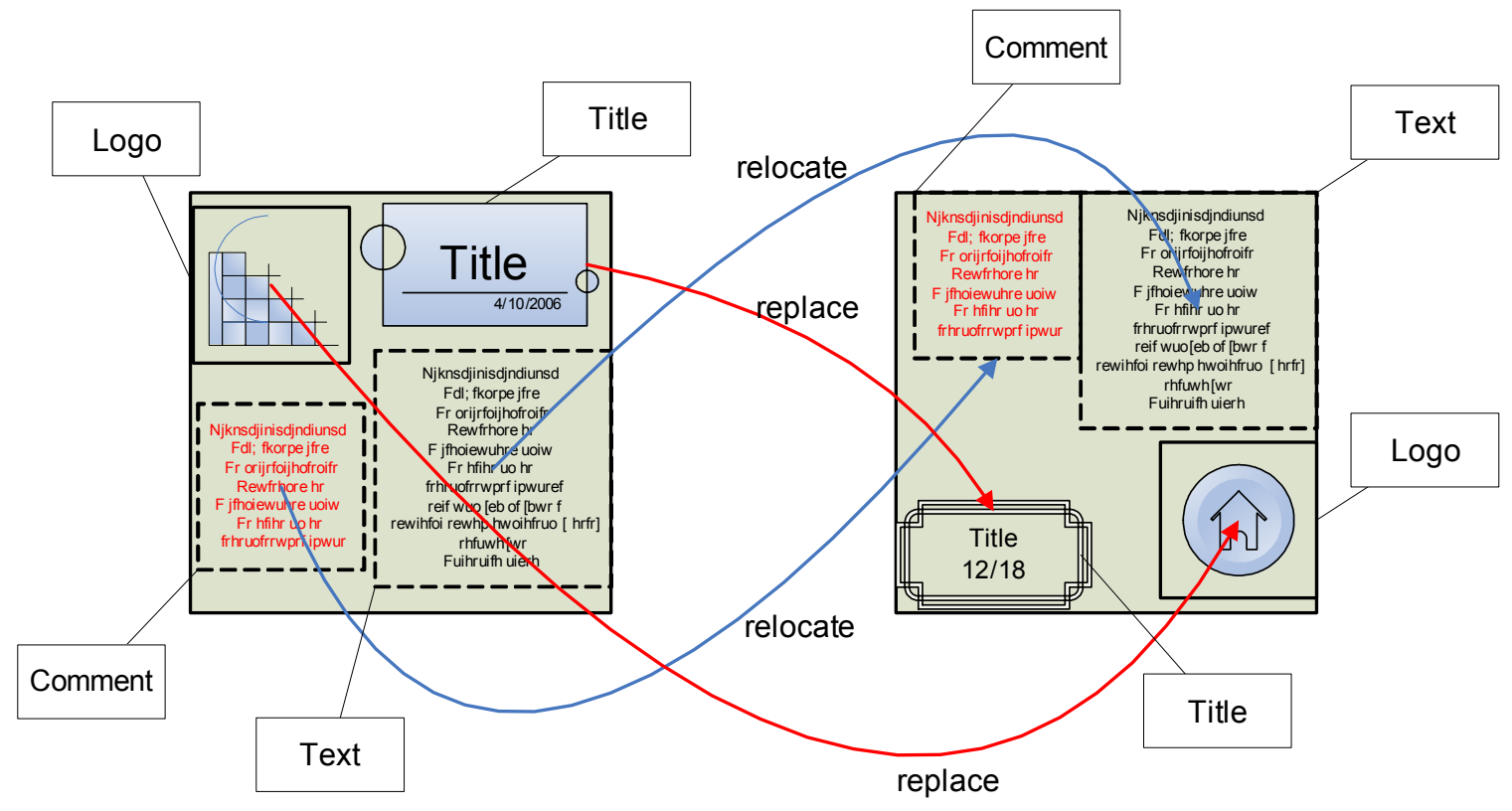

Figure 3. Reassembling Learning Objects

\section{The added value of learning objects}

The flexibility of the Learning Object content model is in the ability to store, locate, and repurpose content as needed. They are large and contain a lot of context. However, they are flexible since their contents can be re-arranged easily to form a new learning collection. As can be seen in 
Figure 4, we have a different look and feel for a course by moving the text or comment components (drawn with a dotted line) or by changing the format of the title or logo components. The existence of metadata allows re-assembling of content into a more meaningful context.

While there can be any number of levels in this Content Object Model, the four main levels (Krull, 2004) are as follows:

- Data or Raw Media Elements are the smallest level in this model and consist of the "raw media" stored at a pure data level. Examples include a single sentence or paragraph, single illustration, animation, video, audio clip, etc. (e.g. logo, title, text and comment in figure 4 can be of type animation, image and paragraph respectively).

- The second level of Information Objects is formed by a set of these data elements to create a granular, re-usable chunk of information that is media independent. For example, a title, a logo, a text or a comment entity with no type specified. Information objects are self descriptive, can be mutated and assembled in an application (a title object has a special meaning in a learning module, when it appears in an application that support graphics it will appear as image, or else as text).

- Based on a single objective, Information Objects are then selected and assembled into the third level of Application Specific Objects. This is the level in the hierarchy for one of the most common types in use today, the Learning Object (LO). The learning object specifies the conceptual and positional structure of a basic learning module that can be displayed diversely (i.e. a web page, a screenshot, a presentation or a printed page that combines a title, a logo, a text and a comment entity in a $2 \times 2$ matrix).

- The fourth and fifth levels are defined around the larger (terminal) objectives to create Aggregate Assemblies such as lessons or chapters, which can in turn be assembled into ever larger Collections which might be such things as courses and whole curricula.

The content object model presented in figure 3 has been adopted by big learning software vendors such as Autodesk Inc (www.autodesk.com/)

\section{E - Learning Functional Model}

Once the building blocks of the learning process have been defined we should explain how they are used, which tasks are dedicated to their creation, assembly, delivery, consumption and evaluation and which tools are employed in every task (O'Droma, Ganchev, \& McDonnell, 2003). All the tasks, tools and users are the components of the e-learning environment and the learning objects are the entities that must be transferred among them. In Figure 4 a conceptual model that positions e-learning products and their functionality in terms of an e-learning environment is provided (based on Robson, 2003).

The functional model of e-learning comprises of the Production and Dissemination phases. A Management phase runs in parallel.

The main components of the Production phase are:

- Content Repositories: they index commercial and custom learning objects that can be retrieved and served to people and systems. They support content management functions such as version control, check-in/check-out, import, export and transfer functions etc.

- Metadata: they are used for indexing and retrieval tasks, especially for non textual content. Learning object metadata is used to describe the structure and location of learning objects and facilitate retrieval. This allows learning objects to be stored on multiple servers with different characteristics. 
- Content Authoring tools and services (RELOAD, 2004) allow education experts and instructional developers to create and modify fundamental learning entities.

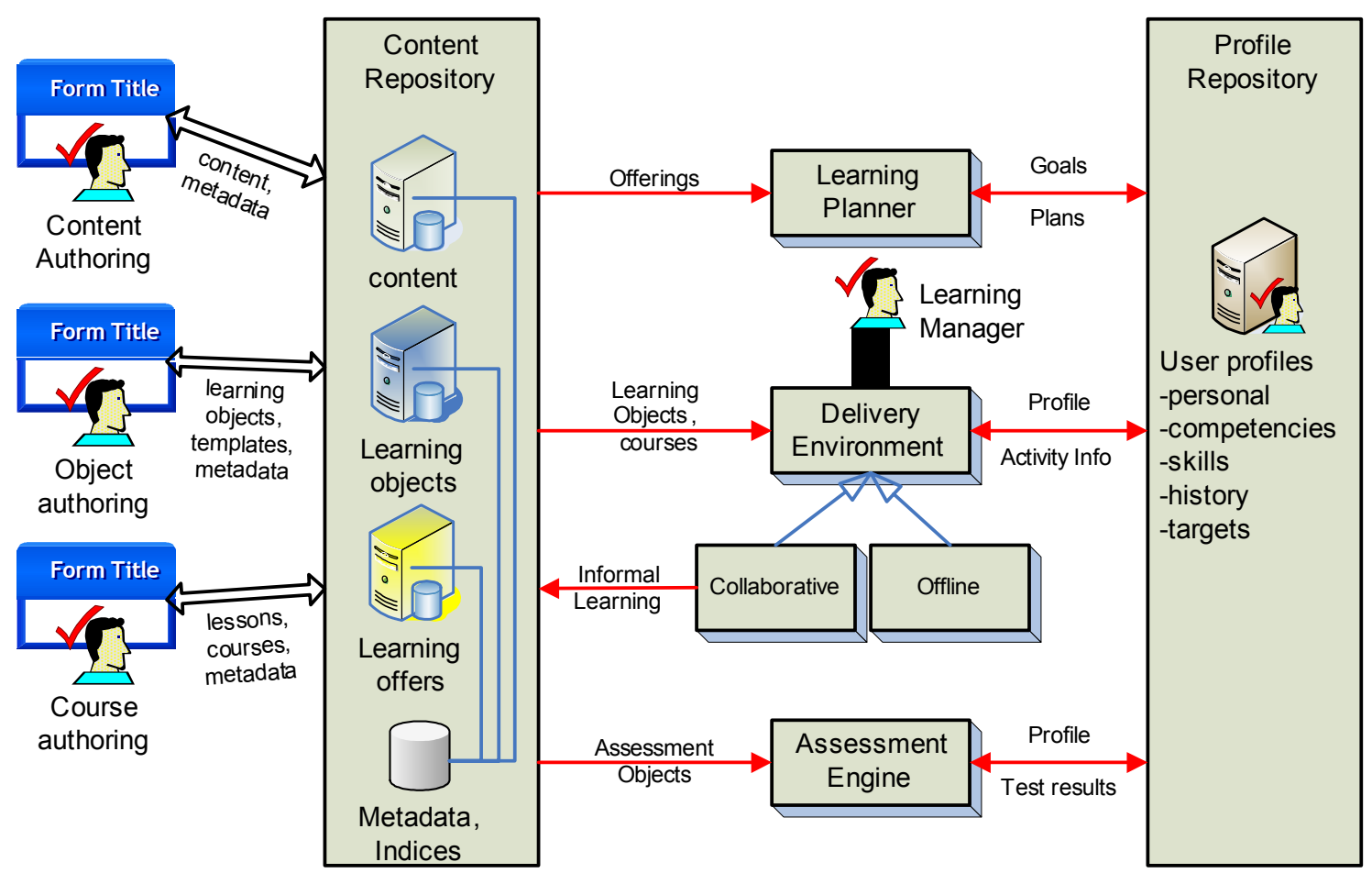

Figure 4. e- Learning Functional Model

- Learning Objects Authoring tools support the assembly of content entities into cohesive learning modules. Assets from the repository are used to fill content templates (Halm, 2003) and create new learning objects. Templates are empty of content and are used from education experts to guide professional teachers in assembling successful learning objects and lessons. Assembly of learning objects and templates is strongly linked with other components and tasks of the learning experience such as educational discussion forums (Harman \& Koohang, 2005) and collaboration environments.

- Packaged course authoring tools (Horton, \& Horton, 2003) support the composition of learning objects into courses (with the inclusion of assessment components) Packaged course solutions are based on learning plans (Stark \& Lowther, 1986) (degree paths, certification paths and skill development curricula) and compose learning objects into complete learning solutions which are put on the showcase.

- Learning Offerings. Packaged course products are indexed and priced (Fallon \& Brown, 2002) based on the accounted market needs so as to become offerings (Vossen \& Westerkamp, 2003). Every small and large educational organization (Pöyry, Pelto-Aho, \& Puustjärvi, 2002) uses catalogues that allow authorized individuals to make learning available and to set access rules, restrictions, prices, and so on.

Once the repository is populated with content, learning objects, courses and learning solutions, the delivery and exploitation of products follows. Many tasks, tools and experts have a crucial role in the dissemination and utilization of learning solutions: 
- Learner Profile Repositories keep information about the learners that use them (Anido et al., 2001). Information includes: personal data, learning targets and history (such as attained or expected certifications and degrees), assessments of knowledge (skills and competencies), and the status of participation in active learning (registration, progress).

- Learning Planners such as teachers (Ellington, 2000), advisors, career counsellors, human resource managers (L'Allier, \& Lacoff Resner, 2004) etc assist learners to determining their targets, to evaluate and improve their profiles based on a concrete plan.

- Delivery Environment. Comprises tools and activities such as chat, email, quizzes, multimedia applications, collaboration tools, application sharing, shared whiteboards, equation editors, etc. that can be offline or online (Nash, 2005) and collaborative (i.e. virtual classrooms). Delivery can also be done informally (informal learning) using live conversations, presentations, informal training, hands on demonstrations etc.

- Assessment and Testing may be integrated with learning content and delivered with it. Learners' performance is recorded and learners' profiles are updated.

Learning Management Systems (LMS) are intended to manage the learning environment and synchronize production and dissemination tasks. Full featured Learning Management Systems (such as those provided by LearnTone (LearnTone, 2006), IBM Mindspan Solutions, Saba and Thinq (Saba, 2006), integrate authoring, assessment, and delivery tools and provide: a) management of learner profiles and learning offerings, b) learning planning, c) authoring, delivery and tracking of content and assessment.

Learning Content Management Systems - LCMS (Chapman \& Hall, 2001) - are multi-user environments where learning developers can create, store, reuse, manage, and deliver digital learning content from a central object repository. An LMS manages the processes surrounding learning whereas an LCMS manages the process of creating and delivering learning content. The features of typical LCMS products include: a) content authoring and assembly, b) registration, storage, and retrieval of objects based on standards.

\section{E-learning Standards}

The adoption of standards and specifications facilitates the dominance of platform independent, open technologies and promotes user-centric e-learning systems. Standardized technologies have several merits that protect and nurture an e-learning investment. These are in general:

- Interoperability: Content from multiple providers can be easily disseminated within consumers and a multitude of systems. Problems of translation, communication, information exchange are easily solved and transparent interaction of systems is achieved.

- Re-usability: Content and code can be assembled, disassembled, and re-used quickly and easily. Additionally content objects can be adapted and used in a context other than that originally designed.

- Manageability: Systems can track the appropriate information about the learner and the content. Learners' profiles, educational target and content "speak the same language" so it is easier to find, manage and assembly "the right stuff" for each case.

- Accessibility: A learner can access the appropriate content at the appropriate time on the appropriate device. Content warehouses can be developed and become available to amateurs or professionals that use any application based on the common standards. 
- Durability: Content is produced once and transplanted many times in different platforms and systems with minimum effort. Buyers are not "trapped" by a particular vendor's proprietary learning technology and their investments become permanent and adverse to risk.

- Scalability: Learning technologies can be expanded in functionality in order to serve broader populations and organizational purposes. An organization's return on investment in e-Learning products can increase if they can be leveraged beyond their original scope.

The standardization of procedures in e-learning can be achieved through the co-operation of all participants of the e-learning community: developers, vendors and users should work together in order to create, validate, establish and disseminate standards for every e-learning task.

\section{Four Steps for the Establishment of E-Learning Standards}

The four steps for setting up standards for the e-learning community as depicted in Figure 5 are explained in details in the paragraphs that follow.

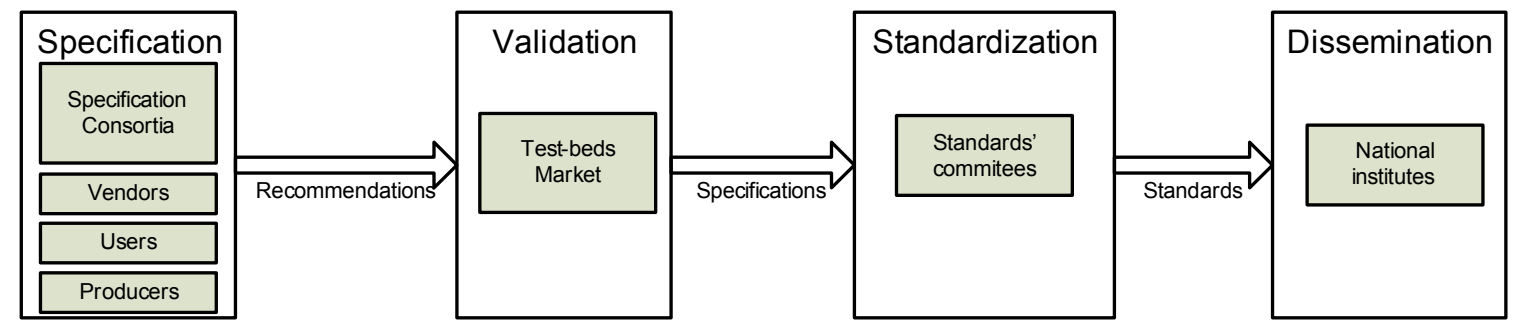

Figure 5. Steps for establishing e-learning standards

\section{Specification}

Co-operating organizations should first define the tasks they carry through the learning process and the respective needs for standards. The requirements analysis is followed by an in-depth description of the e-learning process workflow. All information exchanges between tasks and all procedures should be properly specified and documented. The workflow description is communicated among partners and is refined to cover all possible tasks and avoid repetitions. The detailed analysis is expected to reveal inefficiencies and the role of experts in this phase is to issue recommendations for future specifications.

The needs analysis and the specification of requirements are currently held by consortia such as:

- IMS Global Learning Consortium (www.imsglobal.org),

- CEN/ISS Workshop on Learning Technology (www.cenorm.be/isss/Workshop/lt/ ),

- Customized Learning Experiences Online - CLEO, which involves IBM, Microsoft, Cisco, NetG, and click2learn, (http://www.lsal.cmu.edu/lsal/expertise/projects/cleo/)

- Aviation Industry CBT Committee (www.aicc.org/), and

- HR-XML Consortium (www.hr-xml.org/).

\section{Validation}

Based on the market and workflow analysis performed in the first step and on the suggested specifications, vendors develop new products that incorporate the new requirements. They initiate pilot programs that test the effectiveness and usability of the new products, and establish test-beds for validating their conformance to the specifications. Products that fail the tests are abandoned, and similarly specifications that do not cover user needs are reformed. 
The integration and interoperability of potential standards is first priority during the validation process. The output of the validation step comprises many reference models which show how different specifications and standards work together to support a complete e-learning environment.

Organizations creating test-beds and reference models for e-learning include:

- Advanced Distributed Learning initiative - ADL/SCORM (www.adlnet.org),

- Advanced Learning Infrastructure Consortium - ALIC (www.cen-ltso.net ),

- Education Network Australia - Edna (www.edna.edu.au ).

\section{Standardization}

The third step comprises: a) the refinement of specifications in order to avoid repetitions, to become concrete and clear to users, b) the consolidation of competing efforts into a single output, c) the clarification of conformance requirements in order to avoid misunderstandings and incompatibilities, and d) the official recognition of standards by international organizations and comities. It is important to clearly distinguish between a specification, which is an evolving work in progress, in which many individuals and organizations may offer their recommendations, and an accredited standard, which is ideally based on actual implementations and experience, and provides very clear and unambiguous criteria for implementation and conformance.

Bodies creating accredited standards for e-learning are:

- IEEE Learning Technology Standards Committee (ieeeltsc.org), and

- ISO/IEC Joint Technology Committee Subcommittee on Standards for Learning.

National standards bodies such as the British Standards Institute are also starting to produce accredited standards. These generally have less impact until brought to a pan-national level. CEN/ISSS can produce accredited standards with great regulatory weight in Europe, but their Workshop on Learning Technology intends to work through the IEEE and ISO/IEC, not through CEN/ISSS.

\section{Dissemination}

The final step for the establishment of standards is the dissemination of the widely accepted standards to all the participants of the e-learning community. New members should be informed on the existing standards and old members should become aware of the accredited standards and update their processes to conform. The decisions of international organizations should become accredited by national comities and disseminated to local users and producers. The e-learning communities all over the world should become aware of the new standards and should be supported to better understand them and apply them to their e-learning processes.

\section{Interoperability of E-Learning Technologies}

Figure 4 presents a simplified version of an e-learning environment. Functional e-learning components are provided by a number of vendors and are not constrained by enterprise, technological and geographical boundaries. Institutes and individuals choose the best solutions to achieve knowledge. In order to facilitate integration of e-learning components, vendors provide interfaces for information exchange. However, it is still very difficult and costly to implement an integrated learning environment in the absence of standards.

E-learning interoperability standards provide structures and protocols for creating and communicating e-learning objects. Products that incorporate such standards can be easily integrated and work together effectively. The most important issues on the interoperability of e-learning tools 
and technologies which in the same time attract the attention of standardization organisations are: content description (metadata) and packaging, learner management and communication of the educational process results. In the following we present in more detail these four issues, point out the neuralgic spots, list the organizations that support the standardization process and their contribution.

\section{Content Description (Metadata)}

Content is the nucleus of e-learning. Learning content and catalogue offerings must be labelled in a consistent way to support the indexing, storage, discovery (search), and retrieval of learning objects by multiple tools across multiple repositories. Data used for this purpose is referred to as learning object metadata.

Several initiatives are creating metadata standards:

- The IEEE Learning Technology Standards committee has almost approved the Learning Object Metadata (LOM) standard (LOM, 2002), which has been adopted and adapted by the IMS Global Learning Consortium, the Advanced Distributed Learning initiative, the Alliance of Remote Instructional and Distribution Networks for Europe, and other organizations. LOM provides descriptions ("metadata") for all the components ("learning objects") in order to facilitate finding relevant learning objects. The specification covers technical and educational aspects, property rights, learning object lifecycle and classification and other issues.

- The Dublin Core Metadata Initiative (dublincore.org) has its own metadata standard for e-learning which is used by libraries, publishers, government agencies, and other organizations. In collaboration with IEEE, Dublin Core Initiative aims to put the two standards in a common framework. The available set of metadata elements describes the format and type of the resource, the creator and rights.

- The IMS Learning Design team is developing an Educational Modelling Language (IMSGC, 2003a), which can typically describe the entire pedagogical methodology of a course. This will bridge the gap between high level and machine interpretable descriptions.

\section{Content Packaging}

Content packaging specifications and standards allow courses to be transported among different systems. Packaged learning content can potentially be created by one tool, modified by another tool, stored in a repository maintained by one vendor, and used in a delivery environment produced by a different vendor. Content packages include: a) raw content, b) assembly, delivery and presentation information. Initiatives dealing with content packaging include:

- The IMS Content Packaging specification (IMSGC, 2003b) (commercialized as LRN by Microsoft and supported by multiple vendors),

- The IMS Simple Sequencing specification (IMSGC, 2003c),

- Aviation Industry CBT Committee guidelines and recommendations for computer managed instruction (specifically their notion of a course structure file),

- The Advanced Distributed Learning initiative (ADL) Sharable Content Object Reference Model (ECMA, 2004; SCORM, 2005), based in part on Aviation Industry work, and

- The IEEE Learning Technology Standards Committee, currently putting the Aviation Industry and SCORM work through the accreditation process. 
Assessments and their component questions are a special kind of learning content currently supported by a different set of specifications. As with learning content, we have questions, tests, and test banks that can be transported among systems. The IMS Question and Test Interoperability specification (QTI) is an attempt of standardization in assessment packaging and delivery.

\section{Learner Management}

Learner management requires a standardized description of learner profile data, registration information and privileges.

Learner profile standards allow different system components to share information about learners across multiple system components. Profile information comprises of personal data, learning plans, learning history, accessibility requirements, certifications and degrees, assessments of knowledge (skills/competencies), and the status of participation in current learning. The most important standardization efforts are:

- The IMS Learner Information Package (LIP) specification,

- The Public and Private Information - PAPI (http://edutool.com/papi/) specification that was originally an IEEE draft and is now being looked at by ISO.

Learner registration information allows the controlled delivery of learning content to the learners, based on the offerings available and on learners' choices. The delivery system should be aware on the learners' profiles and privileges in order to deliver content. This implies exchange of offering and enrolment data among learning systems. There exist two initiatives currently dealing with these requirements in e-learning:

- The IMS Enterprise working group that has created a specification for registration data exchange.

- The Schools Interoperability Framework - SIF (http://www.sifinfo.org/), which supports the exchange of this type of data in the K-12 environment.

\section{Communication of Results}

In order to provide feedback to content and course creators we need to generate performance reports (Varlamis, Apostolakis, \& Karatza, 2005). As a learner interacts with content or assessments, activity and performance information is generated that should be communicated to content creators. In order to share the status of learning activities and learners' results across multiple components of a learning environment we need standards. This can be accomplished by creating standardized communication protocols and data models that allow learning content to communicate with the system that delivered it. Work is going on by in two initiatives:

- The Aviation Industry CBT (Computer Based Training) Committee (AICC) and

- The Advanced Distributed Learning initiative with Sharable Content Object Reference Model (SCORM) project.

AICC (http://www.aicc.org/) is an organization that has developed a set of specifications for: a) the online content - the structure of lessons, and tests and the progression logic philosophy for the whole instructional material of a course, $b$ ) the offline instructional activities - training statistics, student assignments, student access data, etc, c) access and performance data - of students at all levels of courseware presentation (figure 6). The student interaction with the online content and the performance in offline activities is a valuable piece of information that must be stored, analyzed and used as feedback for appropriately delivering the course (both offline and online). The analysis of access and performance data will help us measure the individual rate of learning, 
control the quality of the testing $\&$ instruction, determine where and why the courseware is not performing, measure student satisfaction, optimize course path etc. (Varlamis et al., 2005)

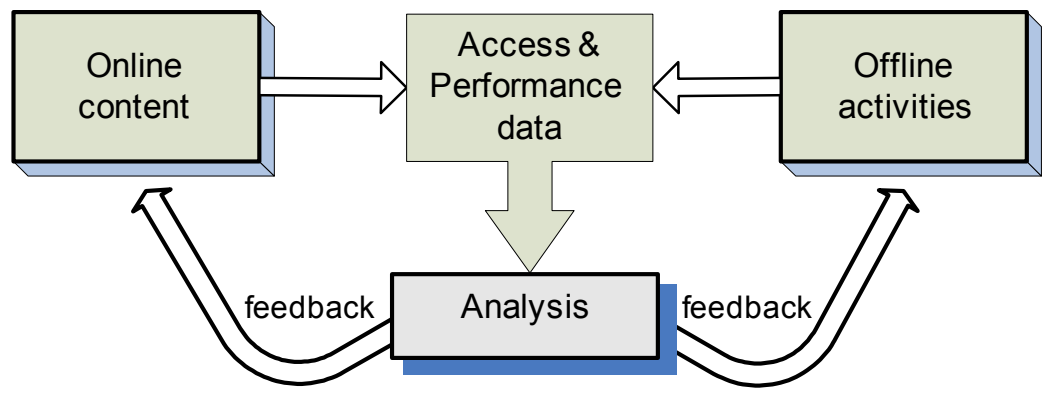

Figure 6. AICC specifications and their interactions

ECMAScript API (ECMA, 2004) and the Data Model for Content Object Communication (IEEE, 2004) are implementation examples which are based on the above specifications. In both cases content is delivered to learners through a server which analyses learners' profiles and statistics and provides the appropriate content to them (Figure 7).

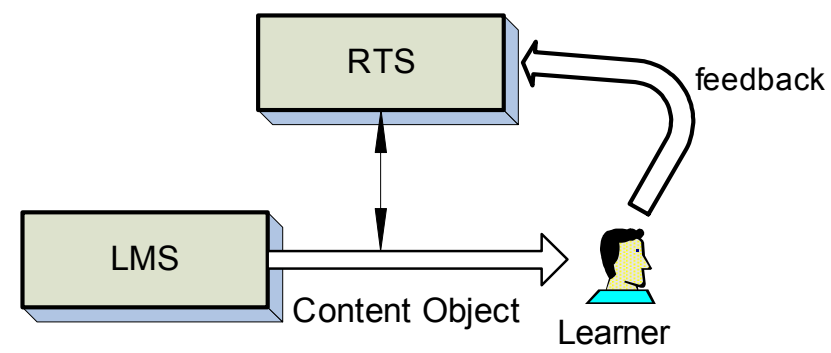

Figure 7. Modelling the interaction of user with content

(SCORM, 2005) is a model for reusable learning content for both computer-based and Web-based (mainly) learning. It provides a harmonized set of guidelines, specifications, and standards based on the work of several distinct e-learning specifications and standards bodies. It builds on accepted Web standards allowing developers to focus on effective learning strategies. SCORM's "technical books" refer to: content (assets, sharable objects), course overview and metadata, content sequencing and navigation (activity tree, sequencing rules), content aggregation (packaging) and runtime environment (i.e. content launch process, standardized communication between content and LMSs and standardized data model elements used for passing information relevant to the learner's experience with the content).

Other interoperability specifications and standards are: the IMS Digital Repositories that standardizes the repository description and offers federated search over multiple repositories, H.323 (videoconference) and T.120 (document conferencing) telecommunication standards by International Telecommunications Union (itu.org), media standards mainly from the World Wide Web Consortium (http://w3c.org ). (HTML, Portable Network Graphics, Synchronized Multimedia Integration Language etc.) 


\section{Conclusions}

It is important to emphasize the fact that learning technology standards implement a certain level of interoperability. In order to achieve the smooth co-operation of all e-learning components we should impose standards in every procedure. Standardization committees should define standards that cover all aspects of the educational procedure and do not cover each other.

A major complaint about e-learning standards is that products claiming conformance do not work together without further tweaking. This translates into lost time and expensive service engagements. As a result of this challenge, there is an increasing emphasis on developing conformance tests and certification programs. It is necessary that e-learning standards must be adopted by everyone without any customization or modification (i.e. based on differences in language, country, low, customs etc.).

The roadmap to achieve standardization of e-learning technologies comprises the following steps:

1. First we should overview the e-learning process as a whole. We must define the operations included in the e-learning process, the information exchanged (input, results etc). In this step we should stabilize the existing practices and record the existing standards and needs.

2. The second step is to locate the main standardization bodies and have them work for the common aim. International boards must decide on the standards by taking into account the needs reported by the national fora.

3. The third step concerns the thoughtful definition of specifications. The specifications should cover all possible needs of e-learning systems and avoid redundancies.

4. The final step comprises the dissemination of specifications and their stabilization into standards. Once they are defined, the specifications are communicated to the community for testing. Additional requirements or modifications are covered in this step. Once approved, the specifications become standards.

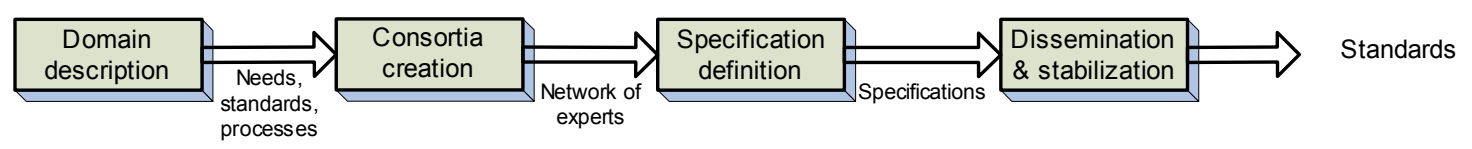

Figure 8. Developing standards for e-learning technologies

\section{References}

Anido, L., Llamas, M., Fernandez, M.J., Rodriguez, J., Caeiro, M., \& Santos, J. (2001). A standards-driven open architecture for learning systems. Second IEEE International Conference on Advanced Learning Technologies, ICALT 2001, p. 3.

Barritt, C., \& Alderman, F.L. (2004). Creating a reusable learning objects strategy: leveraging information and learning in a knowledge economy. San Francisco, California: Pfeiffer.

Bohl, O., Schellhase, J., Senler, R., \& Winand, U. (2002). The sharable content object reference model (SCORM) - A critical review. International Conference on Computers in Education, pp. 950-951.

Bransford, J., Brown, A., \& Cocking, R. (2000). How people learn: Brain, mind, experience, and school committee on developments in the science of learning. National Research Council. Retrieved April 10, 2006 from http://newton.nap.edu/html/howpeople1/ 
Chapman B., \& Hall B. (2001). Learning content management systems. Comparative analysis of systems used to construct, organize and re-use "learning objects." Sunnyvale, CA: Brandon-Hall.com.

Cohen, E., \& Nycz, M. (2006). Learning objects and e-learning: an informing science perspective. Interdisciplinary Journal of Knowledge and Learning Objects, 2, 23-34. Available at http://ijklo.org/Volume2/v2p023-034Cohen32.pdf

ECMA, (2004). ECMAScript application-programming interface (API) for content-to-runtime-services communication (EEEP1484_11_2). Retrieved February 20, 2006 from: http://ieeeltsc.org/wg11CMI/1484.11.3/14113pub/1484_11 3 d6.pdf

Ellington, H. (2000). How to become an excellent tertiary-level teacher. Seven golden rules for university and college lecturers. Journal of Further and Higher Education, 24, 3.

Fallon, C., \& Brown, S. (2002). E-learning standards: A guide to purchasing, developing and deploying standards-conformant e-learning. St. Lucie Press.

Friesen, N., (2005), Interoperability and learning objects: An overview of e-learning standardization. Interdisciplinary Journal of Knowledge and Learning Objects, 1, 23-31. Available at http://ijklo.org/Volume1/v1p023-031Friesen.pdf

Halm, M. (2003). Beyond the LOM: A new generation of specifications. In C. M. Glynn \& R. Acker (Eds.), Learning objects: Contexts and connections. The Ohio State University Press.

Harman K., \& Koohang, A., (2005). Discussion board: A learning object. Interdisciplinary Journal of Knowledge and Learning Objects, 1, 67-77. Available at http://ijklo.org/Volume1/v1p067077Harman.pdf

Horton, W, \& Horton, K. (2003). E-learning tools and technologies. Indianapolis: Wiley.

IEEE. (2004). IEEE standard for learning technology (2004). Data Model for Content Object Communication, IEEE Std 1484.11.

IMSGC. (2003a). Learning design information model, Version 1.0 final specification. IMS Global Learning Consortium, Inc. Retrieved April 10, 2004, from http://www.imsglobal.org/learningdesign/ldv1p0/imsld infov1p0.html

IMSGC. (2003b). IMS content packaging best practice guide", Version 1.1.3. IMS Global Learning Consortium, Inc. Retrieved April 10, 2004, from www.imsglobal.org/content/packaging/cpv1p1p2/imscp_bestv1p1p2.html

IMSGC. (2003c). IMS simple sequencing information and behavior model, Version 1.0 final specification IMS Global Learning Consortium. Inc. Retrieved February 20, 2006 from: http://www.imsglobal.org/simplesequencing/ssv1p0/imsss infov1p0.html

Krull, G.E. (2004). An investigation of the development and adoption of educational metadata standards for the widespread use of learning objects. Master's thesis, Rhodes University, South Africa.

L'Allier, J., \& Lacoff Resner, S. (2004). The competency gap: Aligning education. Chief Learning Officer Journal, 34-37.

LearnTone. (2006), Sun ${ }^{\mathrm{TM}}$ LearnTone learning management system, Retrieved February 20, 2006 from http://www.isopia.com/LearnTone/LearnTone.html

LOM, (2002). Draft standard for learning object metadata. IEEE 1484.12.1-2002, 15 July 2002

Lytras, D.M., \& Sicilia, M.A. (2005). Modeling the organizational aspects of learning objects in semantic web approaches to information systems, Interdisciplinary Journal of Knowledge and Learning Objects, 1, 255-267. Available at http://ijklo.org/Volume1/v1p255-267Lytras_Sicilia.pdf

Masie, E., (2002). Making sense of learning specifications and standards: A decision maker's guide to their adoption. The Masie Centre. Retrieved February 20, 2006 from: http://www.masie.com/standards/S3_Guide.pdf 
Namuth, D., Fritz, S., King, J., \& Boren, A. (2005). Principles of sustainable learning object libraries. Interdisciplinary Journal of Knowledge and Learning Objects, 1,181-196. Available at http://ijklo.org/Volume1/v1p181-196Namuth.pdf

Nash Smith, S. (2005) Learning objects, learning object repositories, and learning theory: Preliminary best practices for online courses. Interdisciplinary Journal of Knowledge and Learning Objects, 1, 217-228. Available at http://ijklo.org/Volume1/v1p217-228Nash.pdf

O’Droma, M., Ganchev, I., \& McDonnell, F. (2003). Architectural and functional design and evaluation of e-learning VUIS based on the proposed IEEE LTSA reference model. Internet and Higher Education Journal, 6, 263-276.

Pöyry, P, Pelto-Aho, K, \& Puustjärvi, J. (2002). The role of metadata in the CUBER system. In Proceedings of the South African Institute for Computer Scientists and Information Technologists (SAICSIT) Conference.

Pukkhem, N., \& Vatanawood, W. (2005). Instructional design using component-based development and learning object classification. Fifth IEEE International Conference on Advanced Learning Technologies (ICALT'05), 492-494.

RELOAD. (2006), RELOAD home page. Available on February 20, 2006: http://www.reload.ac.uk

Robson, R. (2003). The global framework for e-learning. Eduworks Corporation. Presentation at AICTEC 2003. Retrieved February 20, 2006 from: http://www.eduworks.com/Library_E-Learning.html

Saba, (2006), human capital management solutions. Available on February 20, 2006: http://www.thinq.com/, http://www.saba.com/

SCORM, (2005), SCORM Version 1.3, ADL SCORM. Retrieved February 20, 2006 from: http://www.adlnet.org/scorm/index.cfm

Stark, J.S., \& Lowther, M.A. (1986). Designing the learning plan: A review of research and theory related to college curricula. Ann Arbor: University of Michigan, National Center for Research to Improve Post-Secondary Teaching and Learning.

Varlamis, I., Apostolakis, I., \& Karatza, M. (2005). A framework for monitoring the unsupervised educational process and adapting the content and activities to students' needs. WISE Workshops 2005, 124133.

Vossen G., \& Westerkamp P. (2003). E-learning as a web service. Seventh International Database Engineering and Applications Symposium (IDEAS'03), 242.

Wiley, D. A. (1999). The post-LEGO learning object. Retrieved February 20, 2006 from: http://wiley.ed.usu.edu/docs/post-lego.pdf

Wiley, D., (2002). The instructional use of learning objects. Retrieved February 20, 2006 from: http://reusability.org/read/

\section{Biographies}

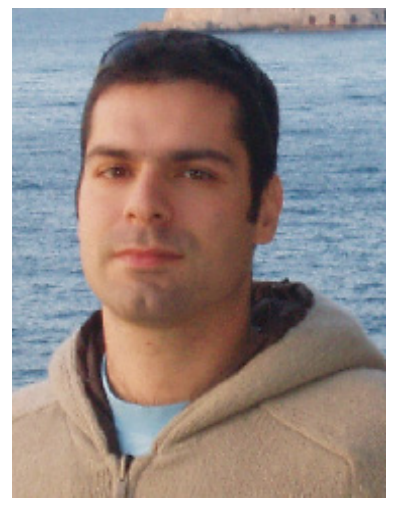

Iraklis Varlamis is a post-doctoral researcher in the Computer Science Department of Athens University of Economics and Business. His research interests vary from data-mining and knowledge management to adaptive educational platforms and educational software. He has written and presented several articles in international conferences, concerning the design and exploitation of modular systems in education. For more information visit: http://www.db-net.aueb.gr/hercules 


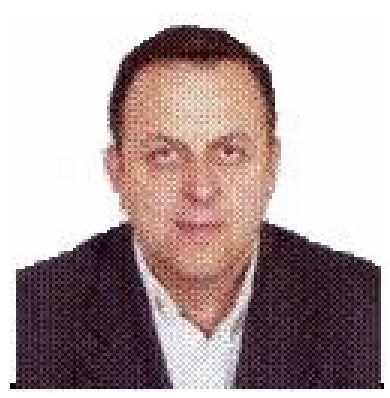

Ioannis Apostolakis was born in Chania of Crete and studied Mathematics in University of Athens. He holds an MSc in Informatics, Operational Research and in Administration in Educational Units, and a $\mathrm{PhD}$ in Health Informatics. He has been for several years Scientific Researcher in the Department of the Clinical Therapeutics in University of Athens. He had been teaching in University of Athens and in Polytechnic University of Crete. Today he teaches to the post-graduate program of the National School of Public Health and to Panteion University. 